University of Nebraska - Lincoln

DigitalCommons@University of Nebraska - Lincoln

10-1999

\title{
The monophyly and relative rank of alticine and galerucine leaf beetles: A cladistic analysis using adult morphological characters (Coleoptera: Chrysomelidae)
}

S.W. Lingafelter

S. Konstantinov

Follow this and additional works at: https://digitalcommons.unl.edu/usdaarsfacpub

This Article is brought to you for free and open access by the U.S. Department of Agriculture: Agricultural Research Service, Lincoln, Nebraska at DigitalCommons@University of Nebraska - Lincoln. It has been accepted for inclusion in Publications from USDA-ARS / UNL Faculty by an authorized administrator of DigitalCommons@University of Nebraska - Lincoln. 


\title{
The monophyly and relative rank of alticine and galerucine leaf beetles: A cladistic analysis using adult morphological characters (Coleoptera: Chrysomelidae)
}

\author{
S. W. LINGAFELTER and A. S. KONSTANTINOV
}

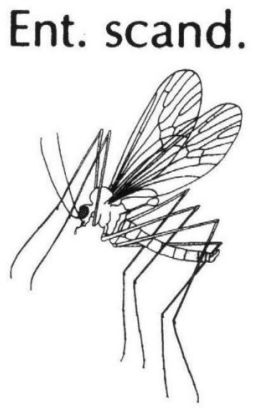

Lingafelter, S. W. \& Konstantinov, A. S.: The monophyly and relative rank of alticine and galerucine leaf beetles: A cladistic analysis using adult morphological characters (Coleoptera: Chrysomelidae). Ent. scand. 30: 397-416. Copenhagen, Denmark. January 2000. ISSN 00138711 .

The first cladistic analysis to determine the monophyletic status of alticine and galerucine leaf beetles and their relationship to one another is provided. A classification based on their hypothesized relationships is proposed. Fifty morphological characters of adults were analyzed from twenty-nine taxa representing six traditionally recognized subfamilies (Orsodacninae, Aulacoscelidinae, Eumolpinae [including Synetini], Chrysomelinae, Galerucinae, and Alticinae), with an emphasis on thorough exemplar representation from galerucines and alticines. Cladistic analyses of these characters using the heuristic analysis of PAUP resulted in 444 equally most parsimonious cladograms, a consensus of which was mostly unresolved. Successive approximations weighting of these trees produced a nearly fully resolved hypothesis of relationships among the taxa. This hypothesis indicates the monophyly of chrysomelines + eumolpines + orsodacnines and monophyly of galerucines + alticines. Importantly, the alticines are a highly derived, strongly supported monophyletic group, nested within galerucines. Therefore, alticines must have a lower relative taxonomic rank (such as tribe) to Galerucinae in order to reflect this phylogenetic hypothesis.

S. W. Lingafelter and A. S. Konstantinov, Systematic Entomology Laboratory, PSI, ARS, USDA, National Museum of Natural History, MRC-187, Washington, D.C. 20560, U.S.A.

\section{Introduction}

The alticine and galerucine leaf beetles constitute the largest and most taxonomically confusing family level taxa in Chrysomelidae with more than 1,000 genera and 10,000 species. Historically, researchers have treated these groups of taxa as differing or equivalent in taxonomic rank, and rarely have they proposed characters as evidence to support monophyly of each group (never for galerucines sensu stricto and only one character, the metafemoral spring, for alticines.) An overview of the literature that specifically relates to the categorical rank of alticines and galerucines is presented. Only papers that provide data on this subject of categorical rank are discussed. Jolivet \& Cox (1996) included several papers summarizing more general works on chrysomelid classification.

Since Latreille (1802) proposed a tribe Galérucites (of equivalent rank to subfamily) that included alticine and galerucine genera, the relative rank of alticines and galerucines to each other as well as to other suprageneric chrysomelid taxa has fluctuated. Alticinae was first recognized as a family group name in Newman's classification of Coleoptera (1835). This fact was neglected by nearly all subsequent authors beginning with Chevrolat (1836), who had 3 categories in his notable catalog: family, genus and species. Newman (1835) provided a short diagnosis of both larval and adult stages of the nominotypical taxon (Altica Geoffroy) and compared this group with Chrysomelinae and Galerucinae, to which he conferred subfamilial rank. He also presented a justification for the taxonomic treatment, stating that adults of galerucines do not leap and have antennae inserted much nearer to each other, unlike alticines. Stephens (1839) was the first to explicitly state justification for his opposing classification in which alticines were considered as a group of 'Galerucidae'. He diagnosed Galerucidae (equivalent to subfamily rank) as having the hinder thighs frequently considerably thickened.' 
Two contradictory points of view coexist in the leaf beetle literature. The first one follows Newman (1835) and treats Galerucinae and Alticinae as closely related but independent subfamilies. This view was shared by Redtenbacher (1874), Jacoby (1908), Heikertinger (1912, 1924, 1941), Heikertinger \& Csiki (1939, 1940), Winkler (1929), Maulik (1926), Ogloblin (1936) and most contemporary chrysomelid taxonomists including Bechyné \& Bechynć (1976), Gruev \& Tomov (1986), Gressitt \& Kimoto (1963), Scherer (1969), Doguet (1994), Mohr (1966), Lopatin (1984), Medvedev (1982), Furth \& Suzuki (1994), and Konstantinov \& Vandenberg (1996).

The second view follows Latreille (1802) and Stephens (1839) who treat alticines as a tribe or subordinate unit of Galerucinae. Allard (1860, 1866), Chapuis (1875), and Horn (1889) followed this classification, and several authors (Böving \& Craighead 1931; Crowson 1955; Lawrence \& Britton 1994; Reid 1995; Crowson \& Crowson 1996) have returned to this idea of combining alticines and galerucines into one subfamily based on the observation that the larvae of both groups are inseparable and transitional forms occur in the adults.

A few recently published papers specifically addressing questions of alticine/galerucine relationships deserve special attention. In an extensive discussion of several morphological structures of adults (mandibles, prothorax, meso-metasternal junction, elytra, wings, metendosternite, male and female terminalia) and larvae, Crowson \& Crowson (1996) proposed a number of characters which can be used to separate most alticines and most galerucines, but none of these features consistently occurs in all members of both groups. They also attempted to establish the primitive condition for these characters but apparently did not come to a conclusion with respect to the alticine/galerucine relationships. Suzuki \& Furth (1992) and Furth \& Suzuki (1994) attempted to resolve the alticine/galerucine controversy by studying so-called problematic taxa (genera which could not be unambiguously assigned to Alticinae or Galerucinae). In the course of their studies they observed certain differences in the metafemoral spring, spermatheca, aedeagus, and wings between alticines and galerucines but none of these differences was constant. The argumentation in these papers makes clear the problem posed by transitional taxa for these characters, yet the authors maintain a subfamilial sister group relationship based on tradition and incomplete laxa examination. Reid (1995) used explicit, cladistic methods to understand relationships among many chrysomelid taxa, but because he lumped alticines and galerucines into one taxon before his analysis, his study also avoided a resolution to the question of monophyly and relative rank of alticines and galerucines. Farrell (1998) using a combination of $18 \mathrm{~S}$ ribosomal DNA and morphological characters from the literature, showed in his analysis of Phytophaga gencra, alticines to be sister group to galerucines, together sister group to chrysomelines.

Our goal is to present for the first time an explicit study to address the question of monophyly and relative relationships among alticines and galerucines. The most defensible way to answer this question is to perform a rigorous study in which diverse, homologous characters are coded and analyzed parsimoniously for members of all lineages of 'Alticinae', 'Galerucinae', and putatively, closely related leaf beetles.

\section{Methods}

Choice of taxa. - In a higher level study such as this, for which we are asking about the basal relationships of two traditionally defined subfamilial lineages, it is impossible, but more important, unnecessary to sample all taxa. This is because unique character changes in highly and recently derived species or genera do not reveal any information about the more basal branching pattern, i.c., the fundamental relationship between alticines and galerucines. Thus, the hopeless task of coding each and every alticine and galerucine is an exercise that does not contribute to the question of whether or not alticines and galerucines are each monophyletic. So, an exemplar approach of taxa reflecting the major lineages and variability within alticines and galerucines, was used in this study.

Using adult specimens from the collections of the National Museum of Natural History (Washington, D. C.) and A. S. Konstantinov private collection (Washington, D. C.), we chose 29 taxa (Table 2) representing 9 traditional galerucine genera including four of the five tribes (Oidini, Galerucini, Sermylini, and Luperini), 12 traditional alticine genera representing 12 major tribes and lineages including Pseudolampsini, Alticini, Aphthonini, Blepharidini, Chaetocnemini, Luperalticini, Diboliini, Disonychini, Psylliodini, and Systenini, and 
8 other genera in potentially closely related clades. A diversity of these related clades was included since there has been a diversity of opinions in sister group relationships to alticines and galerucines: Orsodacninae and Aulacoscelidinae (as potential distant outgroups); Chrysomelinae (considered sister group to galerucines + alticines by Lee 1993 and Reid 1995); Synetini (considered potential sister group to galerucines + alticines by Mann \& Crowson 1981); Eumolpini (considered potential sister group to galerucines + alticines by Mann \& Crowson 1981). These taxa represent the morphological diversity well enough to address our question of alticine / galerucine monophyly and relatedness.

Character coding. - Fifty characters of external and internal morphology of adults were coded for each taxon. Many characters are novel to this study and all have been critically examined by us. Character states were entered into MacClade 3.05 (Maddison \& Maddison 1992). All character states were treated as unordered since there is no a prio$r i$ cvidence of their transformation direction. Therefore, state ' 0 ' does not necessarily imply a primitive condition and ' 1 ' does not necessarily imply a derived state. Transformation from one state to another is equiprobable since there is no evidence supporting any other particular transformation. All characters were given equal weight as there is no evidence suggesting one character carries any more phylogenetic signal than another. The characters and their states are defined in detail in the next section.

Phylogenetic analyses. - To answer the question of whether or not alticines and galerucines are each monophyletic and to determine their respective relationship to one another and other subfamilies of Chrysomelidae, an analysis was made using PAUP 3.1 (Swofford 1991) on a Power Macintosh $8500 / 132$ computer, devoting 35 megabytes RAM to PAUP. Memory and processor limitations required us to use an approximate (heuristic) searching strategy. This used random, simple taxon addition sequences and tree bisection-reconnection methods which decreased the possibility of missing islands of more parsimonius trees. To the set of obtained trees, an a posteriori successive approximations weighting analysis was applied (Farris 1969, Carpenter 1988, Carpenter 1994). This was based on the rescaled consistency index and adjusting this for each character to a scale of 0 to
100. This is discussed further in 'Results and discussion'.

\section{Characters}

Head:

1. Mideranial suture: (0) fully developed (Fig. 1C); (1) present only in lower part or in middle of vertex; (2) absent. The midcranial (or coronal, Snodgrass 1935) suture is the median, dorsal arm of the inverted Yshaped epicranial suture. Its two symmetrically placed, lateral, ventral arms are referred to as frontal sutures (next character). The midcranial suture is a common feature of the leaf beetle head. It is fully developed in Donaciinae, Megascelidini (Eumolpinae), Chrysomelinae, and most Galerucinae. In Hispinae and Eumolpini it is partly developed. Megalopodinae have a poorly developed midcranial suture that is represented by a wide, shallow, slightly longitudinal impression at the base of the vertex, although the clear border between vertex and frons is absent. In Synetini the suture is sometimes marked with a groove, sometimes with a low ridge. The midcranial suture is absent in Orsodacninae, Sagrinae, Lamprosomatinae and Cryptocephalinae.

2. Frontal suture: (0) present (Fig. IC); (1) absent (Fig. $1 \mathrm{~A}, \mathrm{E})$. The heads of alticine and galerucine genera lack the frontal suture. In some specimens, if the antennal calli are well delineated ventrally and/or dorsally by supraantennal and/or supracallinal sulci, one of these grooves could be considered homologous to the frontal suture. However, as discussed and illustrated in Snodgrass (1935), the frontal suture of orthopteroid insects begins at the anteromedial portion of the antennal sockets and continues toward the anterior articulation of the mandibles, a condition clearly not present in most alticines and galerucines. In chrysomelines, the frontal suture is present and situated below the antennal sockets while the supraantennal and supracallinal sulci are situated above the sockets. In other leaf beetle taxa including Donaciinae, Sagrinae, Zeugophorinae, Megascelidini, Hispinae, Cassidinae, Lamprosomatinae, Eumolpini and Cryptocephalinae, the frontal suture is present. Clytrinae possess a vestigial frontal suture. In Megalopodinae, the genal and anterolateral area of the head is so greally modified that the frontal suture is hidden although there is a moderately well defined transverse groove in between the antennal sockets which could be interpreted as the frontoclypeal suture. In Orsodacninae and synetine Eumolpinae, two possible interpretations can be made: Either the frontal suture is well developed and the clypeus is extremely narrow (in the case of Synetini, the clypeus is lost) and poorly delineated from frons, or the frontal suture is absent, the frontoclypeal suture is well developed, and the clypeus is almost as long as the vertex.

3. Frontoclypeal suture: (0) absent or poorly developed (Fig. 1D); (1) well developed (Figs 1C, 3F). This feature was referred to as the epicranial suture by Snodgrass (1935). An example of an easily identifiable frontoclypeal suture occurs in Chrysolina Motschulsky species, which have it situated apical to the 

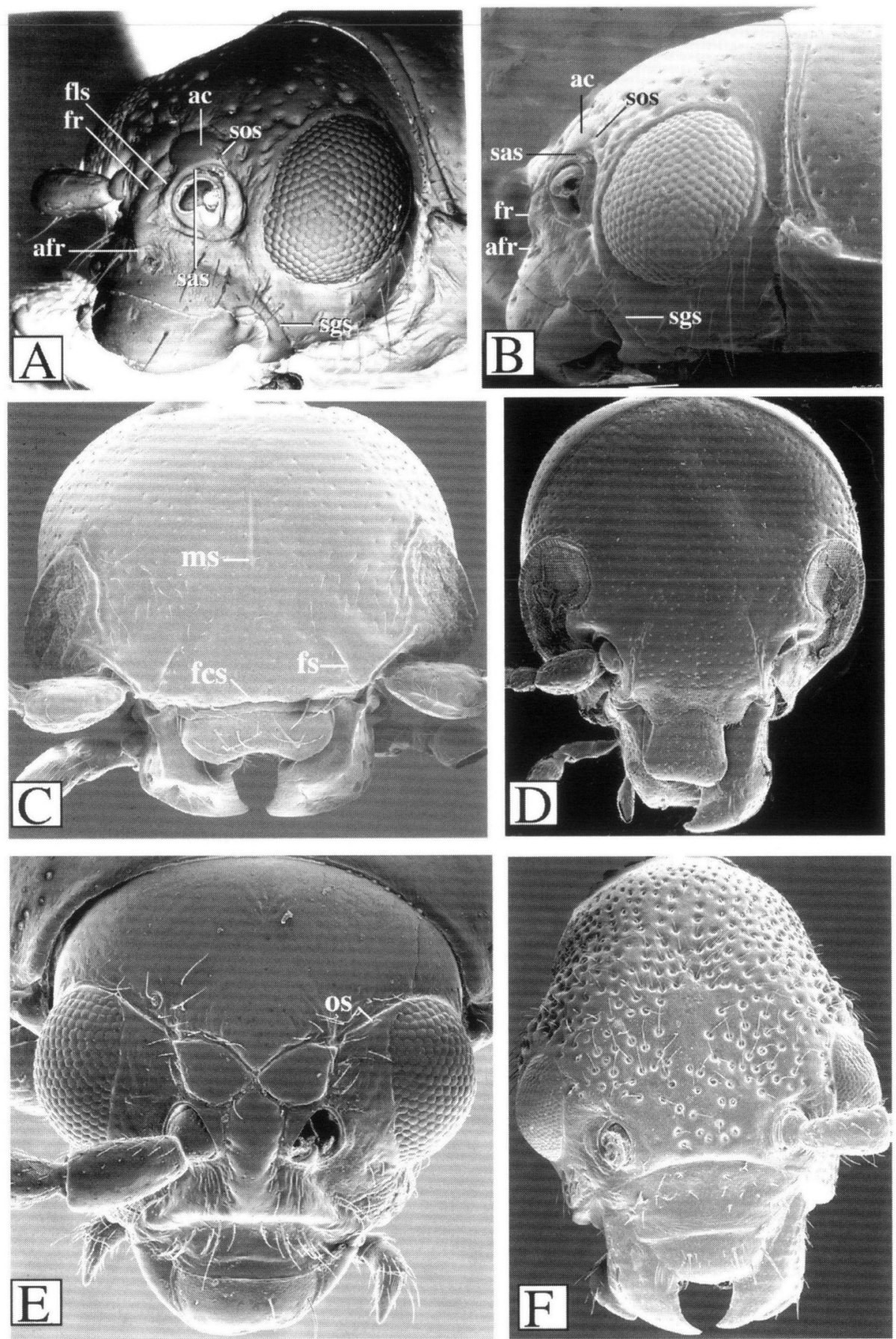

Fig. 1. Heads of leaf beetles: (A) Systena blanda (Melsheimer); (B) same, lateral view; (C) Chrysolina polita (Linnaeus); (D) Eumolpus surinamensis Fabricius; (E) Aphthona cyparissiae Koch; (F) Syneta carinata Mannerheim. ac $=$ antennal callus; $\mathrm{as}=$ antennal socket; $\mathrm{fcs}=$ frontoclypeal suture; $\mathrm{fs}=$ frontal suturc; $\mathrm{ms}=$ midcranial suture; $\mathrm{os}=$ orbital sulcus; sas = subantennal suture; $s g s=$ subgenal suture; $\mathrm{sos}=$ supraorbital sulcus. 

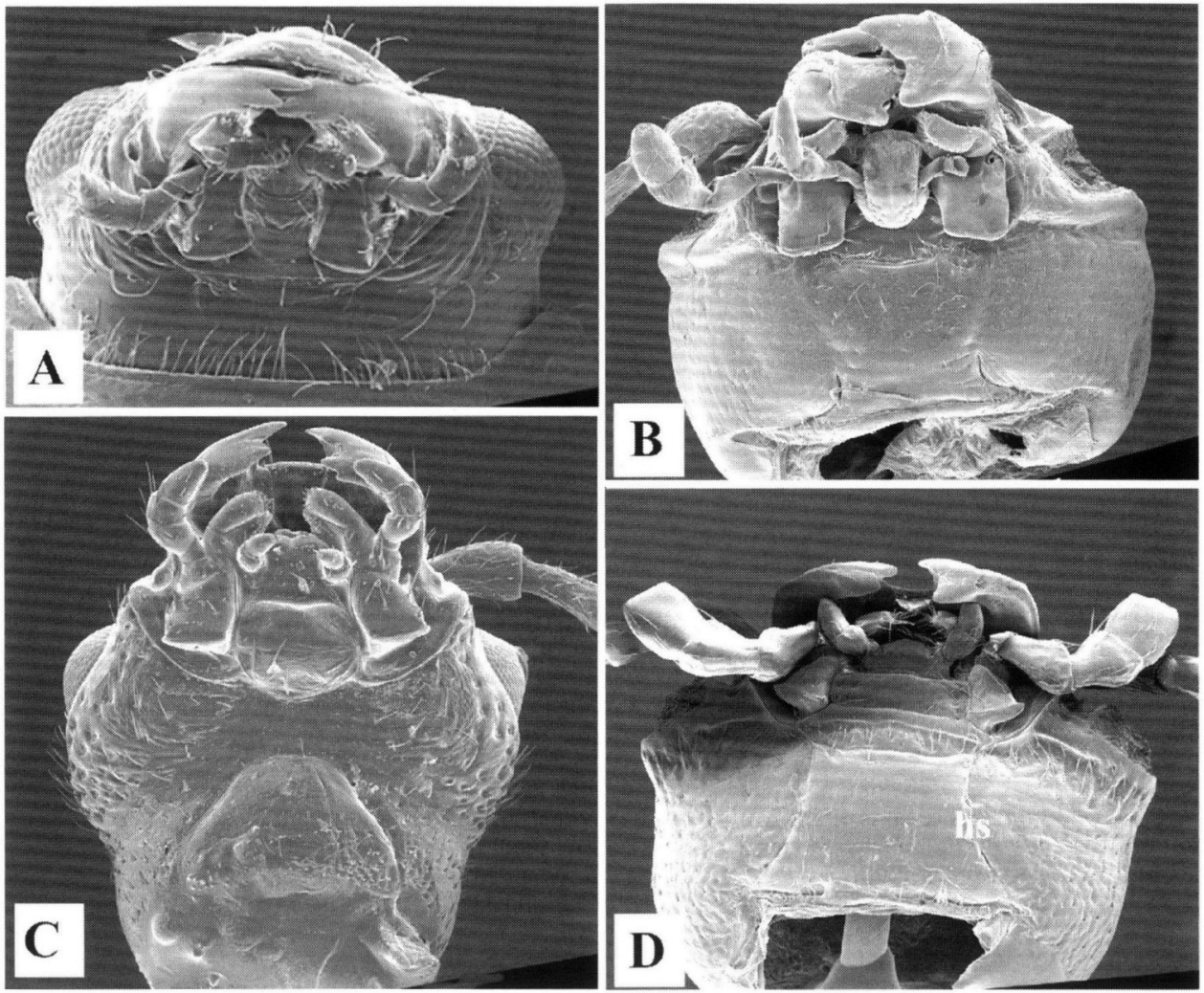

Fig. 2. Heads of leaf beetles, ventral \ iew: (A) Aphthona cyparissiae Koch; (B) Eumolpus surinamensis Fabricius; (C) Syneta carinata Mannerheim; (D) Chrysolina polita (Linnaeus). hs = hypostomal suture.

well developed frontal suture. The well-developed clypeus is usually situated below the level of the frons giving the frontoclypeal suture the shape of a transverse indentation or a 'step' at the apical part of the head. When the clypeus is situated at the same level as the frons, the frontoclypeal suture is usually indistinguishable. In most cases, the frontoclypeal suture is marked by a row of setae. The frontoclypeal suture is absent from Donaciinae, Megascelidini, Eumolpini, and Cryptocephalinac. It is present in Zeugophorinae. Hispinae, Criocerinae and particularly well developed in alticines. In Megalopodinae, there is a moderately well defined transverse groove between the antennal sockets, which could be interpreted as the frontoclypeal suture. This interpretation would mean that the clypeus is extremely long and well sclerotized - unusual in leaf beetles. As with the previous character, in Orsodacninae and Synetini there are two possible intepretations: First, the frontal suture is well developed in which casc the clypeus is extremely narrow (or lost in synetines) and poorly delineated from the frons. Second, the frontal suture is absent. the frontoclypeal suture is well developed, and the clypeus is almost as long as the vertex.
4. Subgenal suture: (0) absent or poorly developed; (1) present (Fig. 1A, B). The subgenal suture is a groove along the anterolatcral margin of the head which, according to Snodgrass (1935), continues medially in some insects to become the epistomal suture. According to our observations, the subgenal and frontoclypeal sutures are independent. The frontoclypeal suture is extended beyond the genal part of the head. Moreover, the frontal end of the subgenal suture sometimes forms the beginning of the subantennal suturc. The moderately well developed suturc is common in flea beetles and most other galerucines. In most chrysomelines, megalopodines, and donaciines, the subgenal suture is present; however, in beetles with a short gena the subgenal suture is less obvious.

5. Subantennal suture: (0) present; (1) very shallow, poorly developed; (2) absent. The cockroach head presents the classic example of the subantennal (formerly called frontogenal) suture, where it extends from the upper part of the subgenal suture to the lower margin of the antennal socket (Snodgrass 1935). This suture can be confused with the lower part of the frontal suture but is defined here by its connection with the antennal socket. In many leaf beetles 

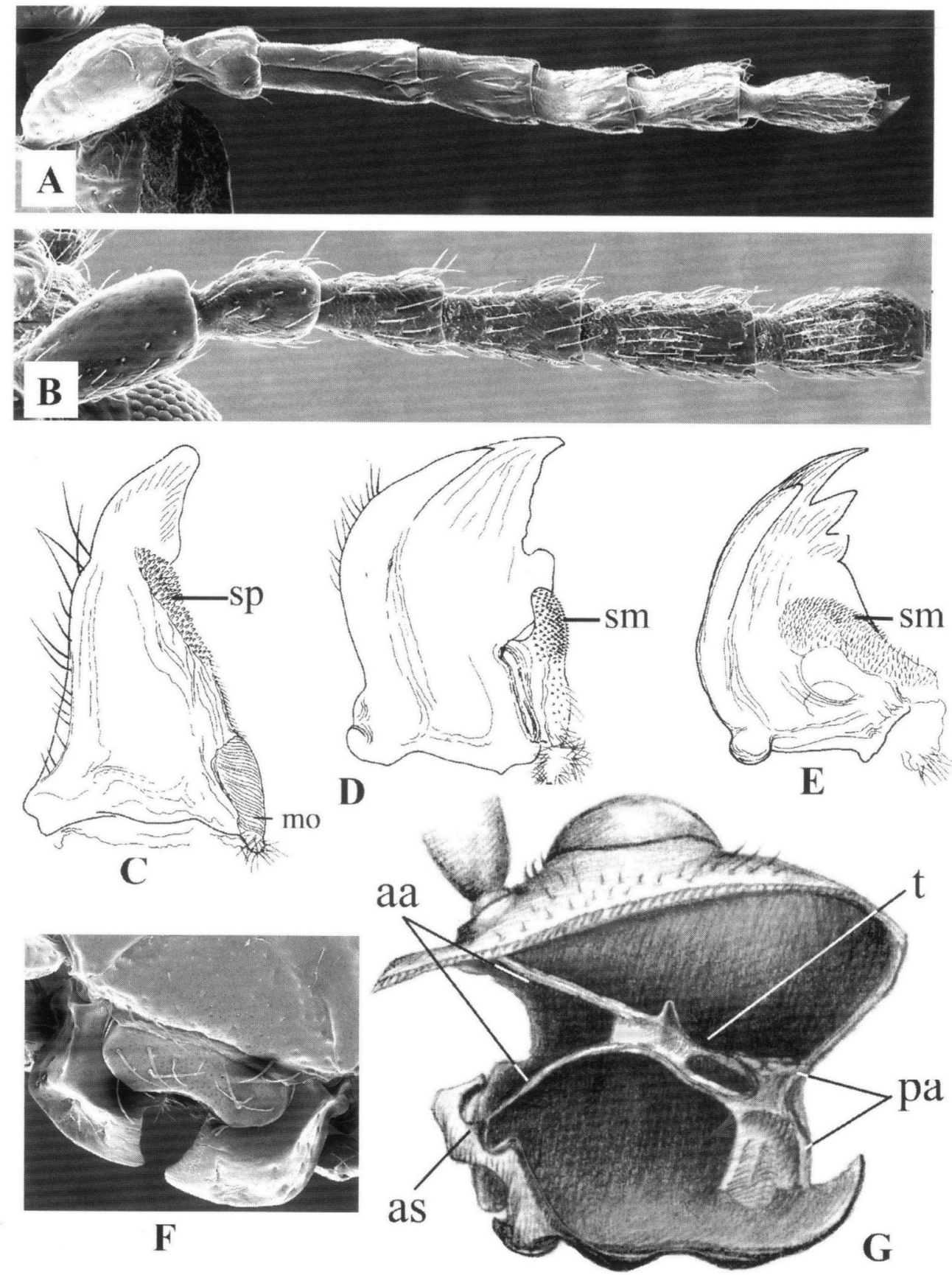

Fig. 3. Antennomeres, mandibles, and head characters of leaf beetles: (A) basal antennomeres of Chrysolina polita (Linnaeus); (B) basal antennomeres of Aphthona cyparissiae Koch; (C) mandible of Orsodacne atra Ahrens; (D) mandible of Entomoscelis adonidis Pallas; (E) mandible of Monolepta quadriguttata Motschulsky; $(\mathrm{F})$ labrum of Chrysolina polita; $(\mathrm{G})$ tentorium and head characters of Orsodacne atra aa $=$ anterior tentorial arms; as = antennal socket; $1 \mathrm{~s}=$ labral setae; $\mathrm{mo}=$ mola; $\mathrm{pa}=$ posterior tentorial arms; $\mathrm{sm}=$ setose membrane; $\mathrm{sp}=$ setose plate; $\mathrm{t}=\mathrm{ten}$ torium. 
with eyes situated close to the head margin. this suture is absent. In some Eumolpinae (including Synetini) and in Donaciinae, it is present, although barely visible and extremely short. Chrysomelinae are polymorphic with respect to this character. Oreina Monrós \& Bechyné. Phratora Chevrolat, and Gonioctena Chevrolat lack this suture while Chrysolina and Colaphellus Weise have it. This suture is absent in Orsodacninae, Megalopodinae, Zeugophorinae, Megascelinae, Sagrinae, and most alticines, but present in some Hispinae and Criocerinac. The Lamprosomatinae have an indistinct groove covered with large punctures between the upper appendage and antennal socket, which could be considered as remnants of the suture. Some Clytrini (e.g., Labidostomis Germar) have this condition while Cryptocephalus Müller and C/ytra Laicharting do not. Chloenus is unique with its well-developed frontal sutures and poorly developed, laterally situated subantennal sutures.

6. Antennal callus: (0) absent (Fig. 1C, D, F); (1) poorly developed with margin poorly defined and surface sculpture differing from surrounding region; (2) well developed (Fig. 1A, E). Antennal calli are elevations of the cranial wall above the level of the vertex, situated dorsal to the antennal sockets. They are absent in Megalopodinac, Orsodacninae, most Eumolpinae (including Synetini), Zeugophorinae, Lamprosomatinae, and clytrine Cryptocephalinae (e.g., C/ytra). In Hispinac and Cassidinae there are two elongate, low elevations of the cranial wall behind the antennal sockets, not delimited from the latter by sulci. Also, because the antennal sockets of these beetles are widely separated. these structures do not give the appearance of antennal calli, but they are probably homologous based on their position. A similar condition occurs in Donaciinae, Cryptocephalinae (Cryptocephalus and Labidostomis), and in some Eumolpinae. In Criocerinae these structures are also present, along with two additional, similar structures dorsally on the vertex. The head of Chrysomelinae and Blepharida Chevrolat and Psylliodes Berthold flea beetles has poorly developed antennal calli.

7. Supraorbital sulcus: (0) absent or merely a row of punctures; (1) shallow or consisting of a few long and parallel wrinkles: (2) well developed. deep (Fig. $1 \mathrm{~A}, \mathrm{~B})$. The supraorbital sulcus separates the area of the antennal callus and orbit. It originates from the dorsolateral side of the antennal socket and continues dorsally along the internal margin of the eye to the end of the antennal callus. It is variable among the taxa examined.

8. Orbital sulcus: (0) absent (Fig. 1A, B); (1) situated close to eye margin and poorly developed, sometimes consisting of a few long and parallel wrinkles; (2) well-developed, originating at the end of the antennal calli (the homology of this character is difficult to demonstrate if the antennal calli are absent) (Fig. 1E). In contrast with other sulci, the orbital sulcus is fairly common in leaf beetles. It is well-developed in Criocerinae, Donaciinac, Sagrinae, Lamprosomatinae, some Cryptocephalinae (Cryptocephalus), and Eumolpinae. It is absent or poorly developed in most Clytrinae and Chrysomelinae.

9. Hypostomal suture: (0) present, fully developed, reaching hcad margin (Fig. 2B); (1) present, incomplete, not reaching head margin (Fig. 2D); (2) absent (Fig. 2A). The hypostomal suture is situated on the ventral surface of the head and lies between the posterior tentorial pits and anterior margin of the head. It separates the gular area of the head from the postgena or gena (in the case when the border between these areas, the occiputal suture, is absent).

10. Antennal sockel location on head: (0) situated far apart on the lateral sides of the head (Fig. 1C, D, F); (1) close to each other on the dorsal or dorsolateral sides of the head (Fig. IA, E). The relative distance between the antennal sockets is a well known and widely used key character for separation of eumolpines and chrysomelines from galerucines, alticines and hispines (c.g., Lopatin 1984). All alticines and galerucines we studied have the antennal sockets close to each other while other taxa have them situated far apart.

11. Antennal socket location relative to eye: $(0)$ close to eye margin (diameter of antennal socket larger or equal to distance between antennal socket and eye; if these distances are nearly equal the distance between antennal sockets is many times greater than their diameter) (Fig. 1D); (1) far from eye margin (diameter of antennal socket smaller than distance between antennal socket and eye; if these distances are nearly equal, the distance between antennal sockets is slightly larger than their diameter) (Fig. 1A, E). The distance between the outer margin of the antennal socket and inner eye margin actually represents the width of the orbit area of the head. In our sample all flea beetles except Blepharida rhois Förster have a wide orbit, while the other taxa share a narrow orbit state.

12. Antennomere 5 length relative to third and fourth: (0) fifth shorter than third and fourth, each (Fig. 3A); (1) fifth longer than third, shorter than fourth; (2) fifth longer than third, subequal to or longer than fourth (Fig. 3B). This character was never used before in leaf beetle taxonomy. Nearly all flea beetles have the fifth antennomere longest (with the exception of Psylliodes, in our sample.) In Psylliodes, in which adults have only ten antennomeres, the fourth antennomere is the longest, longer than third and fifth, suggesting that the fourth visible antennomere in Psylliodes is homologous to the fifth of other flea beetle genera. Therefore the second, third or fourth antennomere is the one, which probably was lost in the cladogenesis of Psylliodes species.

13. Distance between anterior eye margin and base of mandible: (0) eye margin close to the mandibular basc (distance smaller than diameter of antennal socket) (Fig. 1D); (1) eye margin far away from mandibular base (distance equal to or larger than antennal socket) (Fig. IE, F). This character describes the size and position of the eye on the head and also the length of the genal area. Attempting to compare the distance between eye margin and mandible base with the diameter of the antennal socket is not always satisfactory. In some cases the eye margin is far away from the mandible base, but the antennal socket is also wide.

14. Setose membrane on mandible above opening mediad: (0) absent (Fig. 3C); (1) present on top of pros- 

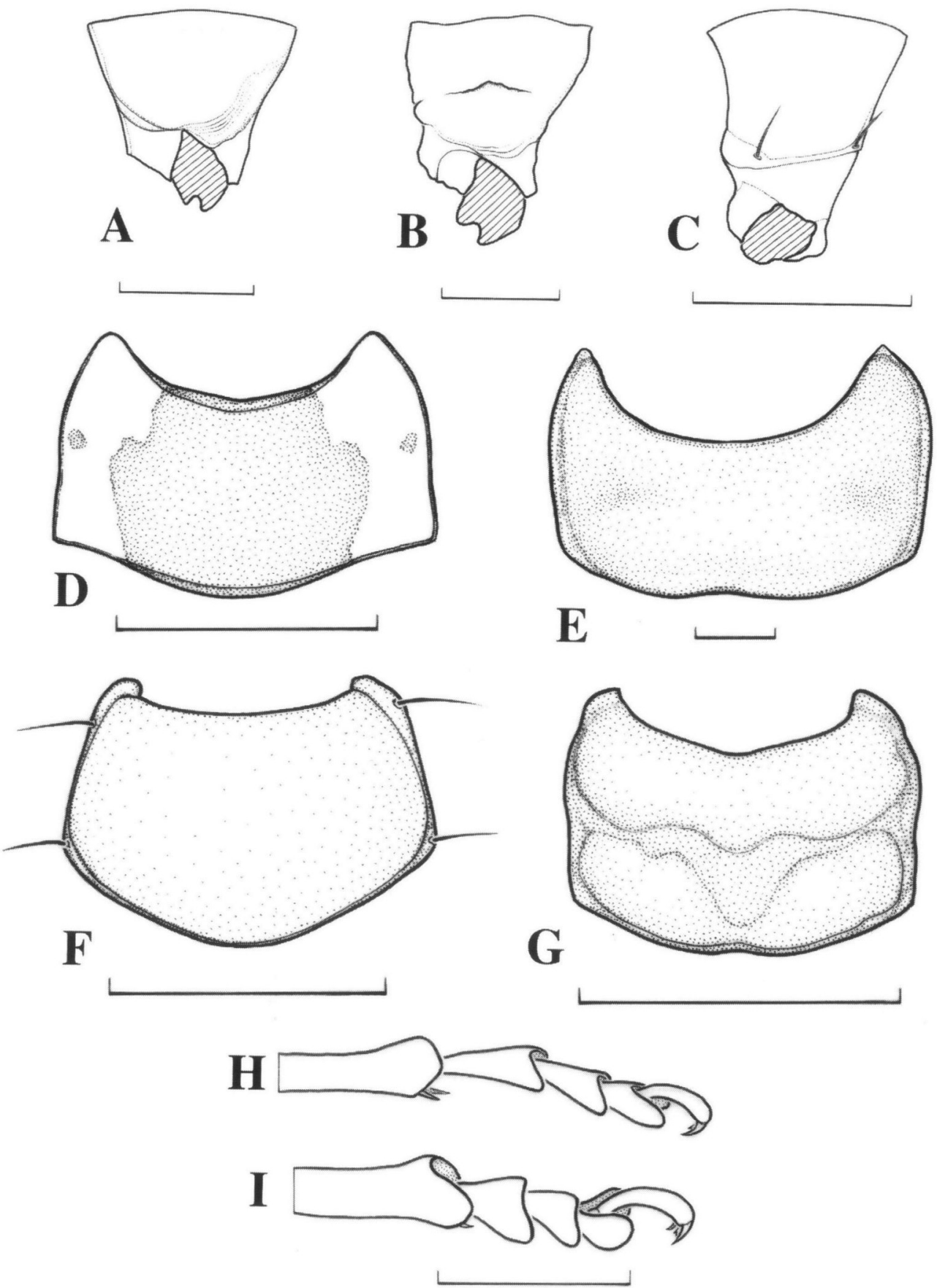

Fig. 4. Pronotal characters and tarsi of chrysomelid taxa: (A) lateral prothorax of Orsodacne atra Ahrens; (B) lateral prothorax of Syneta carinata Mannerheim; (C) lateral prothorax of Psylliodes chalcomera (Illiger); (D) pronotum of Chrysomela collaris Linnaeus; (E) pronotum of Monocesta corylii Say; (F) pronotum of Psylliodes chrysocephala Linnaeus; (G) pronotum of Aulacophora foveicollis Lucas; (H) protarsus of Syneta carinata; (I) protarsus of Blepharida rhois Förster. 

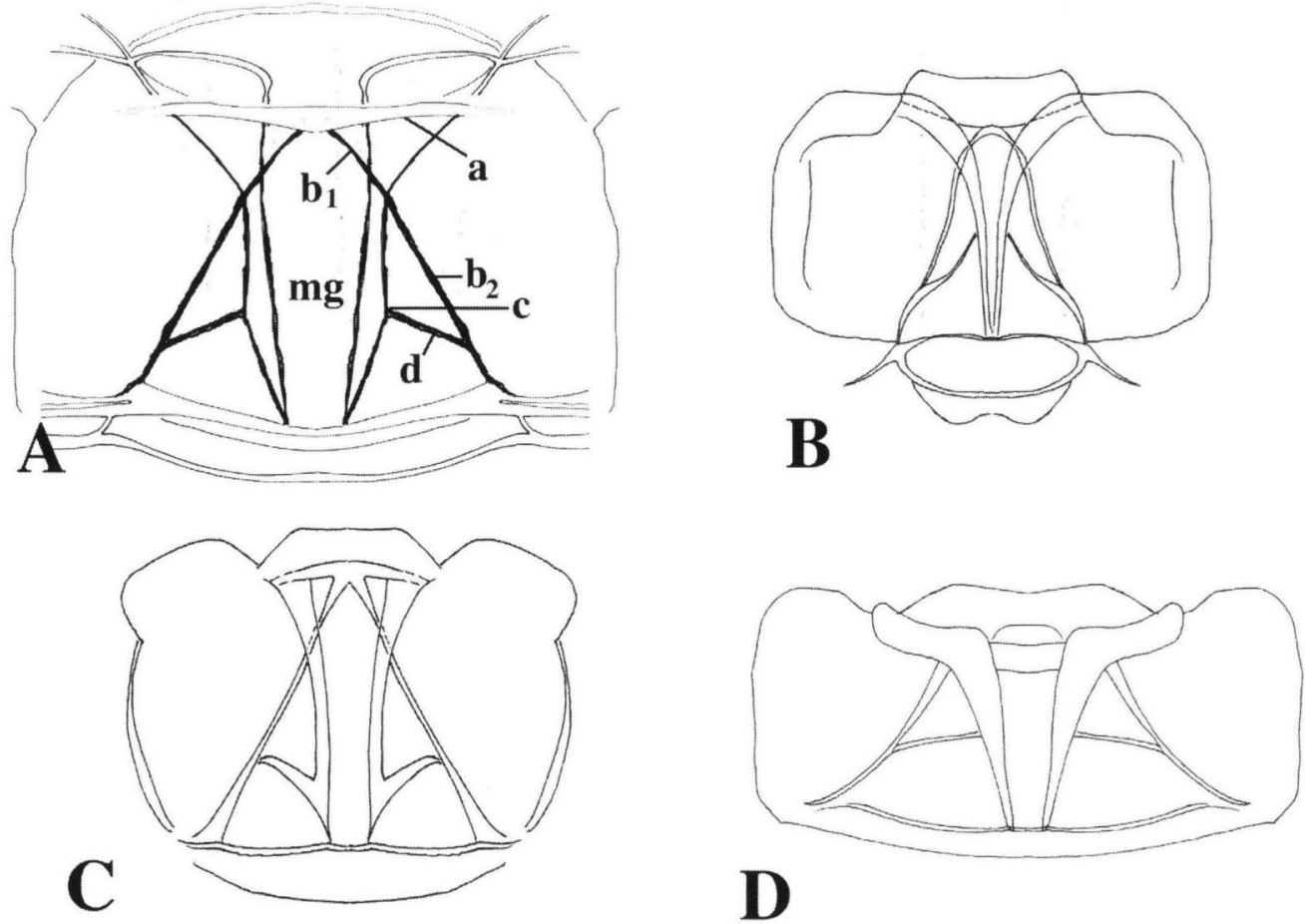

Fig. 5. Metanota of leaf beetlcs; anterior toward top of page: (A) Systena blanda (Melsheimer); (B) Aulacophora foveicollis Lucas; (C) Syneta carinata Mannerheim; (D) Chrysolina polita (Linnaeus).

theca (Fig. 3D); (2) present on inner surface (Fig. $3 \mathrm{E})$. There are two different setose structures on the inner surface of the leaf beetle mandible and this character should not be confused with the setose plate (sce next character). This character is quite complicated to express in writing, but more clear when the illustrations are consulted. The setose membrane, when present, extends from the inner surface of the mandible to above the opening between the mandibles. It is very common among galerucines and alticines.

15. Mandibular setose plate in front of cutting edge: $(0)$ present (Fig. 3C); (1) absent (Fig. 3D, E). This setose plate is much less transparent than the setose membrane (previous character). This plate was observed only in Orsodacne atra Ahrens and Aulacoscelis Chevrolat. It is situated just behind the cutting edge of the mandible and is covered with setulae which are more similar to ampullae. The plate appears thickened and elongated.

16. Mandibular mola: (0) present (Fig. 3C); (1) absent (Fig. 3D, E). The mola is situated at the inner (medial) corner of the ventral surface of the mandible and has a flat shape. The surface is covered with a number of strongly sclerotized ridges. Crows on \& Crowson (1996) considered the presence of the mola in Galerucinae sensu lato as a "primitive character subject to secondary loss but rarely, if ever, regained'. They also found the mola to be present on the man- dible of Neocrepidodera ferruginea (Scopoli). In our sample a well developed mola was found in Orsodacne atra, Aulacophora foveicollis Lucas, and $\mathrm{Al}$ lochroma fasciatus Clark.

17. Shape of terminal maxillary palpomere: $(0)$ inflated, transverse or nearly so apically (Fig. 2D); (1) conical, strongly tapering apically (Fig. 2A, C). This character is present as the conical state in most alticines and galerucines and as the inflated state on chrysomclines and orsodacnines examined.

18. Position of sensillum patch of maxillary palpomere: (0) basal one-third of the terminal maxillary palpomere; (1) medial, approximately centered betwcen the apex and base of the terminal maxillary palpomere. The shape of the sensillum patch of the last maxillary palpomere in leaf beetles was reviewed by Mann \& Crowson (1984). The basal state occurs in most alticines and galerucines, while the apical position occurs in most of the related taxa.

19. Tentorium: (0) branches connected by heavily sclerotized membrane with several ridges (Fig. 3G); (1) branches connected by weakly sclerotized membrane without ridges; (2) anterior arms absent, posterior arms unconnected; (3) anterior arms absent, posterior arms connected. The tentorium, as defined by Snodgrass (1935), consists of an apodeme arching over the ventral nerve cord and extending towards the inner side of the head with anterior and posterior arms. As was already mentioned elsewhere (Kon- 

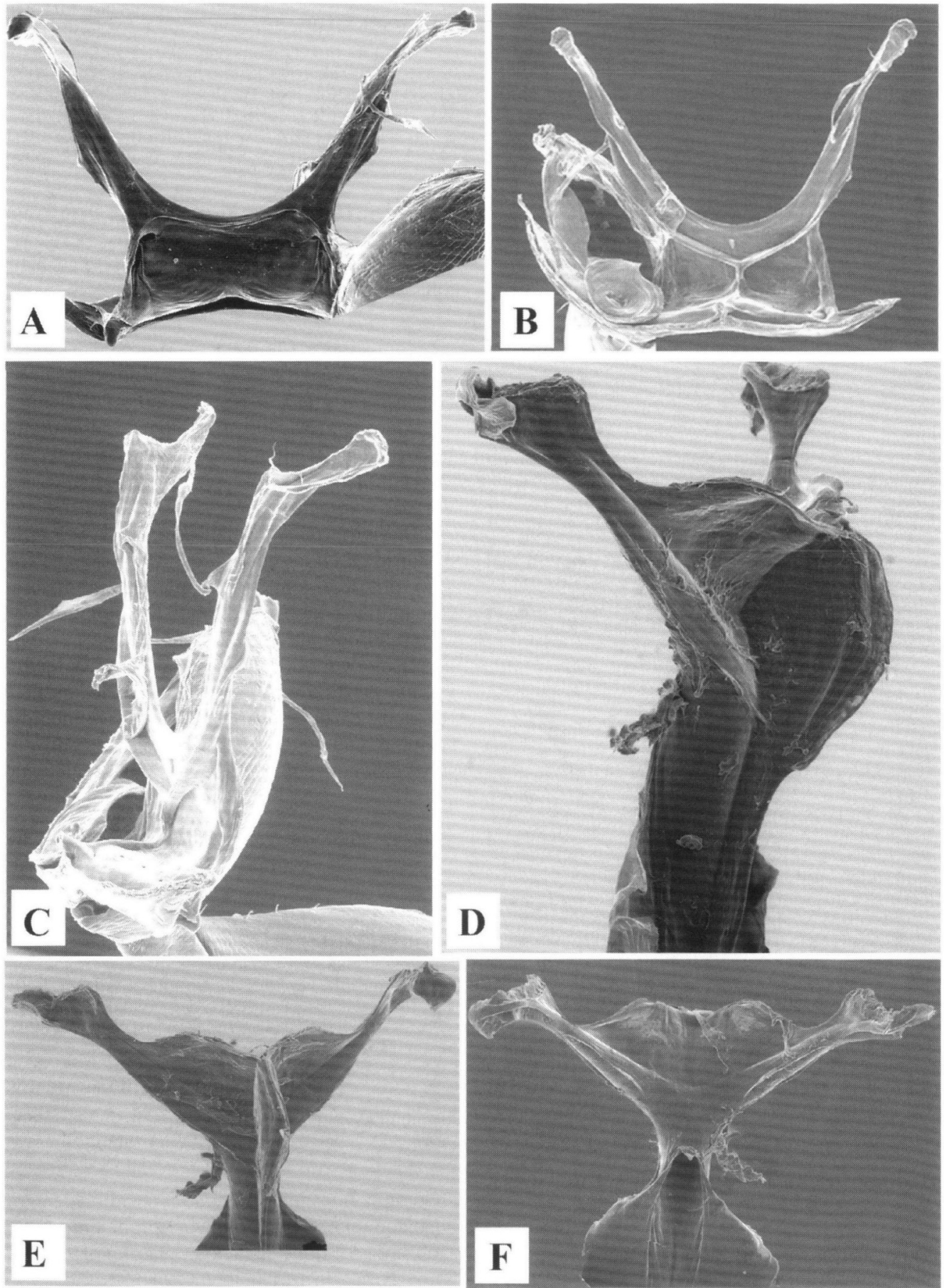

Fig. 6. Metendosternite character states: (A) Orthaltica copalina Fabricius, dorsal view; (B) same, ventral vicw; (C) same, lateral view; (D) Stenoluperus nipponensis Laboissierre, lateral view; (E) same, ventral view; (F) same, dorsal view. 
stantinov 1998b) the tentorium has been misunderstood in leaf beetles and was never used in a comparative study. A complete tentorium of leaf beetles has all the major components including connected ante rior and posterior arms (Fig. 3G), but does not have dorsal arms, despite the barely visible anterior tentorial pits.

20. Head: (0) flat in lateral view, vertex and frons forming nearly straight line; (1) convex in lateral view, vertex and frons forming an angle or with only vertex convex (Fig. 1B). This character refers to the general shape of the head. In our sample it distinguishes most alticines and some galerucines from the other subfamilies.

21. Labral setae: (0) 4 or 6 present; (1) more than 6 present (Fig. 3F). As noted by Konstantinov (1998b) a majority of alticines is characterized by the limited number of setae on the dorsal surface of the labrum. The labrum of chrysomelines and the majority of galerucines has more than 8 long setae. However, specimens of small sized species of Luperus Müller, Stenoluperus Ogloblin, and Monolepta Chevrolat have only six setiferous pores on the labrum.

\section{Thorax:}

22. Lateral extension of pronotal margin: (0) absent (Fig. 4A); (1) incomplete, not extending from anterior to posterior margin (Fig. 4B); (2) complete, extending from anterior to posterior margin (Fig. $4 \mathrm{C}$ ). The lateral margin is not extended in orsodacnines; it is incomplete in synctines; it is fully developed in the remaining taxa including alticines and galerucines.

23. Pronotum antero- and posterolateral corners: $(0)$ not produced, without seta-bearing pores (Fig. 4D); (1) both produced with seta-bearing pores (Fig. 4F); (2) only anterolateral corner produced (Fig. 4E); (3) only posterolateral corner produced (Fig. 4G). Most alticines and galerucines have anterolateral and posterolateral corners produced slightly with setae or pores. The other states vary among the other taxa with state ' 0 ' being most widespread.

24. Prosternal process: (0) thin ridge, incomplete; (1) thick ridge, complete. This feature is the extension of the prosternum between the procoxae. In most alticines it extends completely between the procoxae, separating them by at least one-fifth their diameter. In most galerucines it is thin and incomplete, with procoxae very close together.

25. Mesosternal contact with mesepimeron: $(0)$ nearly in contact; (1) widely separated. This character, illustrated for Systena blanda (Melsheimer) in Lingafelter, Konstantinov \& Lee (1998) occurs in only chrysomelines with the widened state.

26. Scutellum versus mesoprescutum: (0) apparently fused from dorsal view; (1) line of demarcation visible from dorsal view. The fused condition, characteristic of most alticines and galerucines was illustrated for Systena blanda in Lingafelter, Konstantinov \& Lee (1998). Orsodacninac, Eumolpini, and most Chrysomelinae have the separated state.

27. Metapostnotum margin: (0) parallel to metanotum and weakly concave (Fig. $5 \mathrm{~A}, \mathrm{D})$; (1) strongly concave (Fig. 5B, C). Most chrysomelines and alticines in our sample had the weakly concave state while eu- molpines and most galerucines had the strongly concave condition.

28. Intersection of 'd' apodeme with 'c' apodeme of metanotum: (0) obviously anterior to midpoint of ' $c$ ' (Fig. 5B, D); (1) approximately at midpoint or posterior to midpoint (Fig. 5A, C). These internal apodemes arc visible externally as suture-like lines on the metanotum. They are discussed in more detail in Konstantinov (1998b) and Lingafclter, Konstantinov \& Lee (1998). The states vary among the higher taxa studied.

29. Metendosternite stalk width: (0) wider than long (Fig. 6A, B, C), arms not obtusely divergent; (1) longer than wide, arms obtusely divergent (Fig. 6D, $\mathrm{E}, \mathrm{F})$. The metendostcrnite is an important structure which has been used to elucidate relationships of beetles (Crowson 1938, 1944). The width of the metendosternite stalk is consistently greater in chrysomelines of our sample compared to other leaf beetles. However, several flea beetles (Hippuriphila Foudras, Podagrica Chevrolat, and Mantura Stephens) not included in the sample also have a wide and short stalk (Konstantinov \& Lopatin 1987).

30. Metendosternite metafurcal-mesofurcal tendons: (0) close to cach other (Fig. 6E); (1) widely separated (Figs 6A); (2) placed at middle of lateral arms. Crowson $(1938,1944)$ considered the close placement of the tendons of the metafurcal-mesofurcal muscles to be more primitive. In our sample most of alticines have the tendons near the middle of the arms.

31. Metendosternite ventral apodeme: (0) absent; (1) present (Fig. 6B, E). In our sample, only chrysomelines lack the apodeme on the metendosternite. In another study, however, (Konstantinov \& Lopatin 1987), the metendosternite of the flea beetle, Orestia alpina Germar was also observed with an undeveloped ventral apodeme.

32. Metendosternite lateral arm apex: (0) deflexed with anteapical projection (Fig. 6A-F); (1) not deflexed (Fig. 7A, B). The anteapical deflection is characteristic of flea beetles in our sample except Chaloenosoma Jacoby. All other taxa examined have the nondeflexed state.

\section{Abdomen/genitalia:}

33. Ninth tergite: $(0)$ present; (1) absent. The ninth tergite is a small, usually poorly sclerotized plate, situated below tergite 8 and above the gut opening. It is present in many leaf beetle taxa including most alticines, galerucines and chrysomelines. In our sample it is absent in Syneta carinata Mannerhein, Eumolpes surinamensis Fabricius, and Disonycha triangularis Say.

34. Rectum sclerotization: (0) heavily sclerotized; (1) weakly sclerotized. The heavily sclerotized condition was only observed in Chrysolina polita and $O r$ thaltica copalina Fabricius.

35. Tignum development: (0) poorly developed (Fig. 8C); (1) well developed (Fig. 8A, B). The typical alticine female genitalia contains an elongate, strongly sclerotized structure attached to the 8 th sternite called the tignum (Konstantinov 1998a). In a few cases when the tignum is undeveloped, the plate of the 8 th sternite is still recognizable. The tignum is 

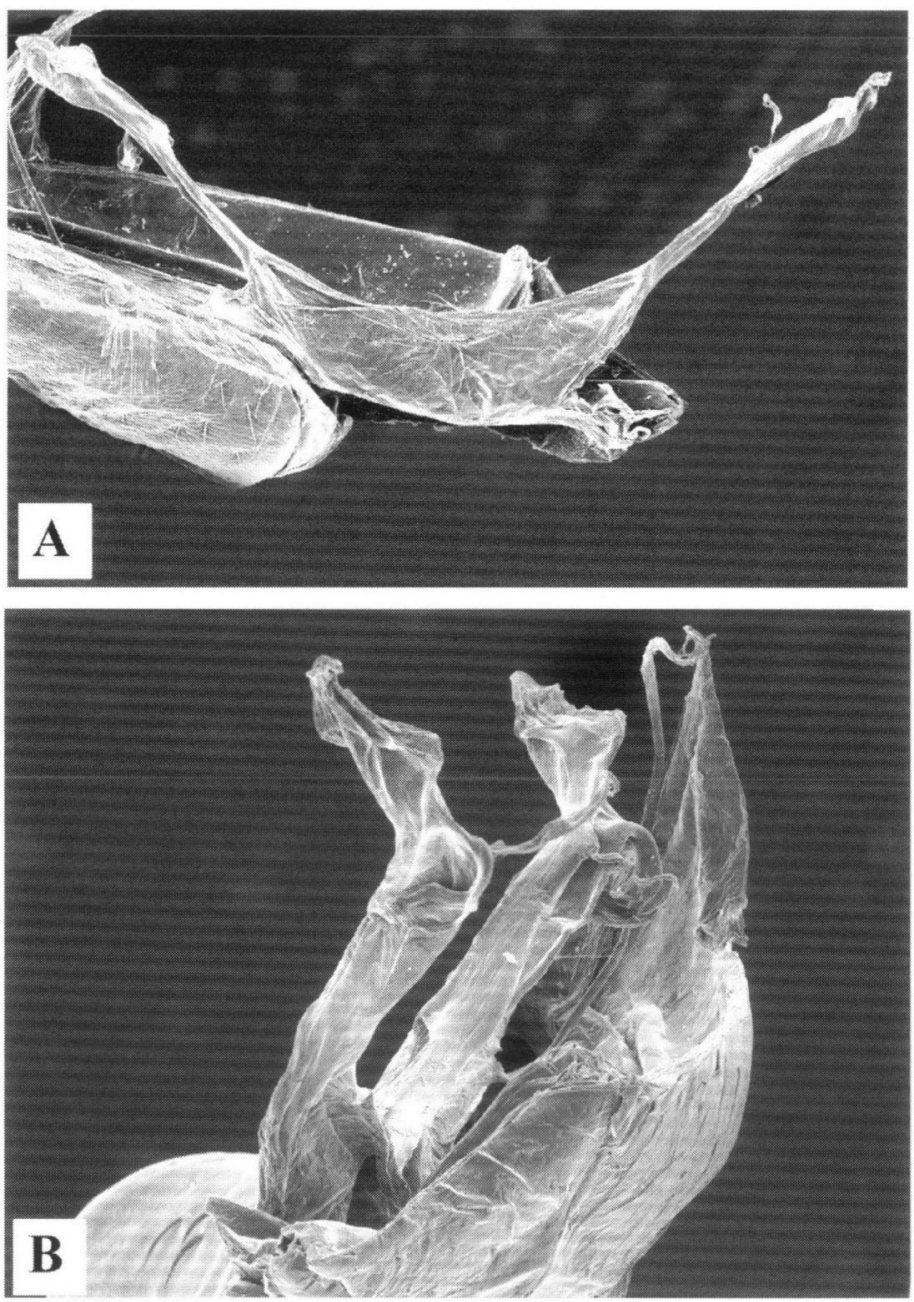

Fig. 7. Metendosternite character states in Chrysolina polita (Linnaeus): (A) dorsal view; (B) lateral view.

well developed in all taxa examined except for chrysomelines and some galerucines.

36. Vaginal sclerotization: (0) strong: (1) absent. The function of the vaginal sclerotization is unclear. The sclerotized state rarely occurs in leaf beetles and does not delimit any taxon at the subfamilial or tribal level.

37. Vaginal palpi: (0) absent; (1) present, without attachment; (2) well developed, with an appendage attached to apex by membrane. The possible homology and function of the vaginal palpi was discussed by Konstantinov (1998a). As a result of that study, we consider paired elongate structures attached to the dorsal wall of the vagina as vaginal palpi. Structures attached to the any tergites or sternites of the female genitalia are treated here as non-homologs to vaginal palpi.

\section{Wings:}

38. Devclopment of RP-MP $:$ (0) connected to $r_{4}$ (Fig. 9D); ( I) not connected to $r_{4}$ (Fig. 9C. E). No alticines examined except Blepharida had this vein connected to $r_{4}$.

39. MP3+4 branch: (0) present and attached to RP-MP (Fig. 9D); (1) absent (Fig. 9C, E). The MP3+4 branch is present only in Orsodacne Latreille, Aulacoscelis, and Etemolpus Weber in our sample. Suruki (1992; 1994) also illustrated state 0 in Sagrinae, Donaciinae, and Megascelinac. 

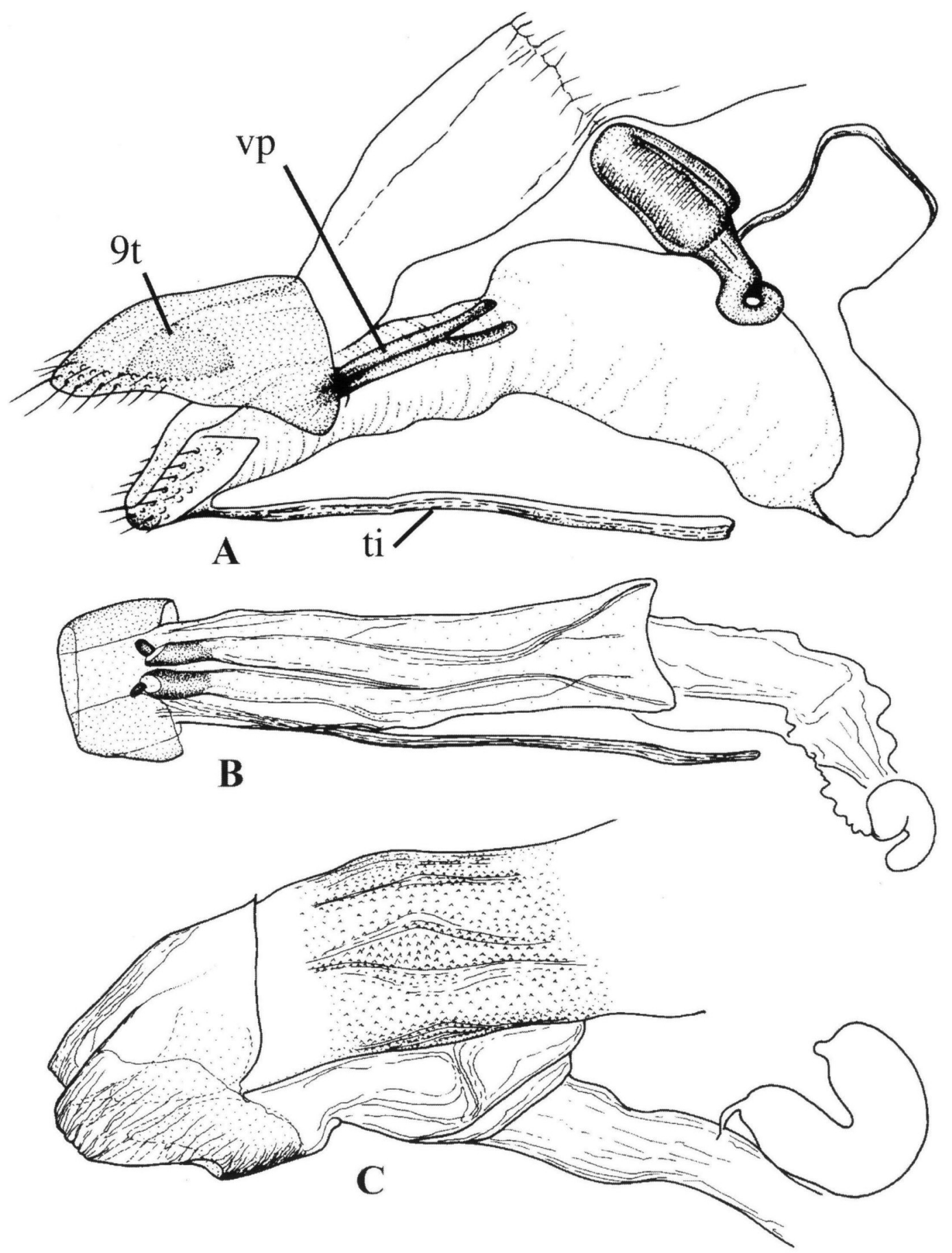

Fig. 8. Female genitalia of leaf beetles: (A) Altica cyanea Weber; (B) Orsodacne atra Ahrens; (C) Syneta carinata Mannerheim. $9 t=$ ninth tergite; $t i=$ tignum; $v p=$ vaginal palpi. 

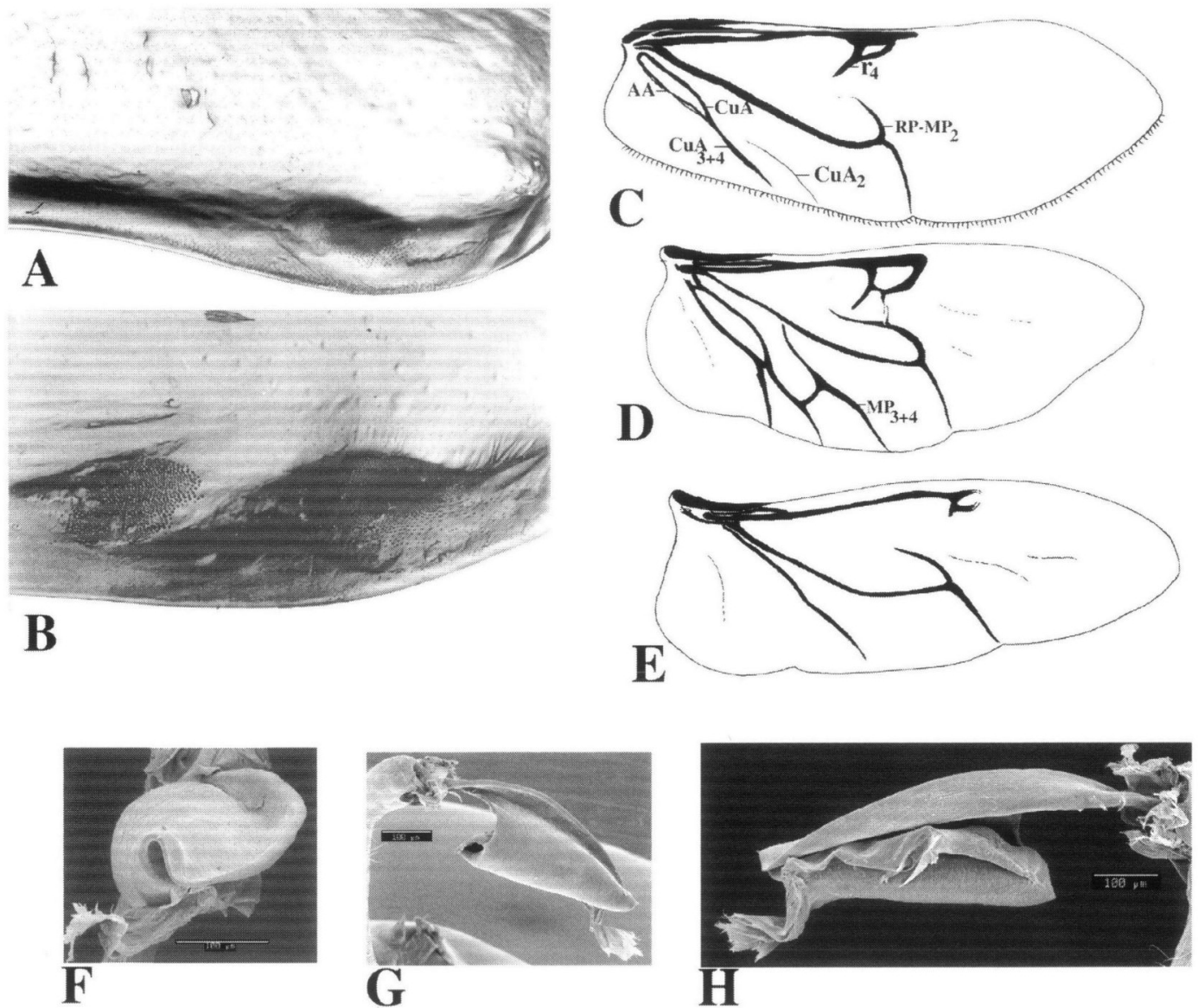

Fig. 9. Elytral binding patch, wing venation, and mctafemoral spring of leaf beetles: (A) elytral binding patch of Trachyaphthona Heikertinger sp.; (B) elytral binding patch of Aphthona violacea $\mathrm{Koch}$; (C) hindwing of Systena blanda (Melsheimer); (D) hindwing of Aulacoscelis melanocera Stål; (E) hindwing of Aphthona cyparissiae Koch; (F-G) metafemoral spring of Systena frontalis (Fabricius).

40. Development of $\mathrm{CuA}_{2}:(0)$ connected to $\mathrm{CuA}$ (Fig. 9D); (1) not connected to $\mathrm{CuA}$, greater than half overall length of $\mathrm{AA}+\mathrm{CuA}_{3+4}$ (Fig. 9C); (2) absent or not connected to $\mathrm{CuA}$ and much less than half overall length of $\mathrm{AA}+\mathrm{CuA}_{3+4}$ (Fig. 9E). Most flea beetles have this vein either absent or much reduced. The development of this vein may be correlated to body size, and thus not a good phylogenetic character.

41. Development of AA: (0) connected to CuA (Fig. 9C, D); (1) not connected to CuA. Most taxa examined have the AA connected to $\mathrm{CuA}$. This vein may be reduced in size in very small specimens and taxa including only small specimens.

42. Binding patch on elytron: (0) single patch present (Fig. 9A); (1) double patches present (Fig. 9B). Most alticines have the divided patch, although in our sample, Sangariola, Disonycha, and Chaloenosoma had one patch. Our findings of the variability of this character within alticines agree with results of Samuelson (1996). Because of these findings, however, and our systematic philosophy, we disagree with his idea of using this single character to reclassify 'problematic' taxa.

\section{Legs:}

43. Third versus fifth protarsomere length: $(0)$ greater than half the length (Fig. 4H); (1) less than half the length (Fig. 4I). Among the examined taxa, only Syneta Dejean had the elongated third tarsomere.

44. Mesocoxa laterad: (0) with anterolateral notch; (1) without notch. A small notch at the articulation of the lateral margin of the mesocoxa with the mesepimeron is present in most taxa in our sample. 

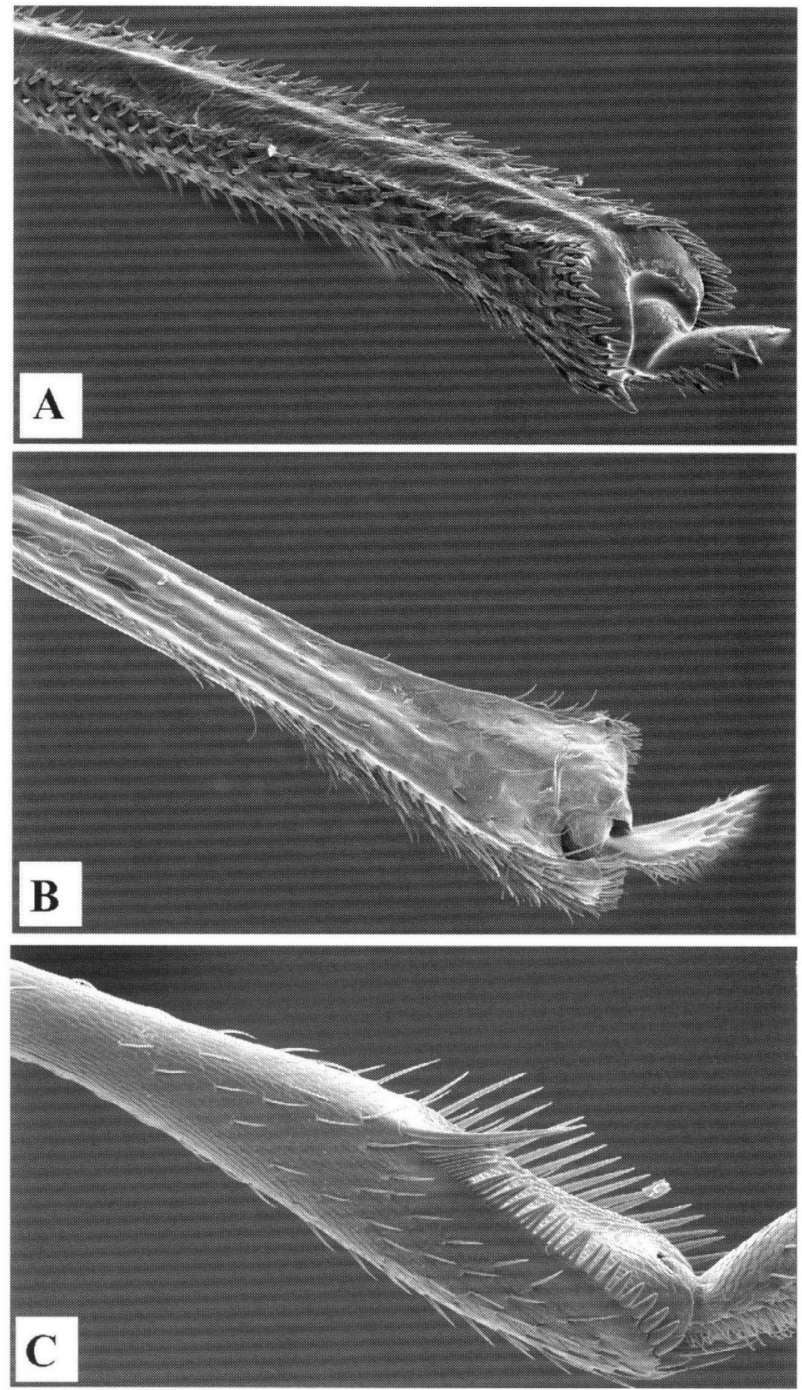

Fig. 10. Metatibiae of leaf beetles: (A) Agelastica alni (Linnaeus); (B) Eumolpus surinamensis Fabricius; (C) Chaetocnema hortensis Geoffroy.

45. Mesocoxal separation: (0) nearly contiguous; (1) widely separated. The mesocoxae are widely separated with a broad mesosternal process in most taxa studied except for many galerucines, orsodacnines, and synetines.

46. Trochantin of mesocoxa: $(0)$ detached from mesosternum; (1) fused to mesosternum. All taxa except Eumolpinae (including Synetini) have the trochantin apparently detached from the mesosternum. In eumolpines, the trochantin of the mesocoxae gives the appearance of fusion to the mesosternum.
47. Separation of metacoxae: $(0)$ narrowly separated (often with narrow anterior process of first ventrite); (1) widely separated (greater than the width of procoxa and often with broad and anteriorly transverse extension of first ventrite). Only the chrysomelines have the metacoxae widely separated.

48. Metafemoral spring: (0) absent; (1) present (Fig. 9F$\mathrm{H})$. This is the fundamental character used to define alticines. It is present in all traditional alticines (as listed in Seeno \& Wilcox 1982) except Orthaltica Crotch. 
Table 1. Data matrix of characters examined for each taxon included in phylogenetic analysis. A) states 0 and 1 present; B) states 1 and 2 present. Character descriptions in text. Full taxon names and authors in Table 2.

\begin{tabular}{|c|c|c|c|c|c|c|c|}
\hline & 00000 & 0000111111 & 11112 & $22222 \quad 22223$ & 33333 & 33334 & $44444 \quad 44445$ \\
\hline Taxon & 12345 & $67890 \quad 12345$ & 67890 & 1234567890 & 12345 & 67890 & 1234567890 \\
\hline
\end{tabular}

\begin{tabular}{|c|c|c|c|c|c|c|c|c|c|c|}
\hline rsodacne atra & 02 & 100 & 00 & 00 & 10 & & 11 & & & 11 \\
\hline Uulacoscelis melan. & 102 & 0020 & 01010 & 11110 & 12010 & 00111 & 1011 & 00 & 100 & 000 \\
\hline umolpus surina. & 02 & 00000 & 00001 & 11110 & 12010 & 11111 & 11111 & 02000 & 1101 & 10011 \\
\hline Syneta carinata & 01012 & 00010 & 00111 & $10 ? 00$ & 11000 & 01 & 0 & 2 & 0 & 1 \\
\hline Chrysolina polita & & & & & 12 & & 10 & 10 & 01 & 1 \\
\hline Chrysomela collaris & 00102 & 10000 & 11 & & 11 & & & & & \\
\hline adon. & & 00 & 00011 & & 11 & & & & & \\
\hline inge. & 00102 & 10000 & 00001 & 10 & 12011 & & & & & 001 \\
\hline a $a / n i$ & 01110 & 11101 & 01021 & 11010 & 12 & & & 10 & & 0000 \\
\hline foveic. & 11100 & 10101 & & & 12300 & & & 10 & 10 & 0000 \\
\hline sica & 01 & 11 & 01 & 1 & 12 & 10 & 0 & 0 & 00 & 0 \\
\hline ceti & 01110 & 12211 & 00021 & 11010 & 12000 & $1 ?$ & 11 & 10 & 00 & 0000 \\
\hline es & 01110 & 20111 & 01021 & & 02100 & & & & & \\
\hline & & & & & & & & & & 0001 \\
\hline esta coryli & & & & & & & & & 00 & 10 \\
\hline gdrig. & 11 & 2 & 01 & 1 & 02 & 0 & 1 & 0 & 00 & 000 \\
\hline nippo. & 11110 & 20101 & 01021 & 11021 & 02100 & 01 & 10011 & 10 & 01 & 00000 \\
\hline roma fascia. & 1111 & 20111 & 12 & 01021 & 02 & 10 & 11 & 12 & 01 & 11 \\
\hline Altic & 21 & & & & 02 & & & 10 & & 1 \\
\hline Aphthon & & & & & & & & & & 1 \\
\hline bis & 11 & 1 & 02 & & 02 & 00 & 11 & 10 & 01 & 11 \\
\hline cnema horte. & 21112 & 22201 & 12121 & 11021 & 02110 & 00012 & 10011 & 11112 & 01 & 00101 \\
\hline enosoma metal & 21112 & 21101 & 11121 & 10 & 02110 & 10 & 11 & 10 & 01 & 00100 \\
\hline Dibolia borealis & 21112 & 22001 & 12121 & 11021 & 02110 & 00 & & 12 & & 11 \\
\hline iangul. & 21112 & 21101 & 11121 & & 02110 & & & & & \\
\hline palina & & & & & 02110 & & & & & 000 \\
\hline & & & 12121 & & 02110 & 00012 & & & 01101 & 00111 \\
\hline Sal & & & 12121 & 11021 & 02110 & 00112 & 10011 & 11112 & 00101 & 00101 \\
\hline Systena blanda & 21112 & $20 ? 1$ & 12121 & $110 \angle 1$ & 02110 & 00112 & 10011 & 11111 & 01101 & 00101 \\
\hline
\end{tabular}

49. Metatibial cross section: (0) cylindrical (Fig. 10A, C); (1) quadrate (Fig. 10B). This feature is variable among the higher taxa included in this study.

50. Metatibial dorso-apical surface: (0) transverse (Fig. 10A); (1) oblique notch (Fig. 10B, C). Most alticines, chrysomelines and eumolpines are characterized by the oblique dorso-apical notch.

\section{Results and discussion}

Analyses. - The heuristic analysis of the data matrix (Table 1; see Table 2 for details on the taxa included) using PAUP resulted in 444 equally most parsimonious cladograms of length 186 with the following statistics: $\mathrm{CI}=0.360 ; \mathrm{RI}=0.688 ; \mathrm{RCI}=$ 0.248 . A strict consensus of these trees resulted in a mostly unresolved polytomy. The taxa Chrysomelinae + Eumolpus + Orsodacnidae + Aulacosce- lis were monophyletic but part of a large basal polytomy with the remaining taxa. Aphthona Chevrolat and Chaetocnema Stephens were a clade, but together part of the large polytomy.

An a posteriori weighting algorithm was applied to the data to reveal phylogenetic pattern when taking into consideration differential character impact. Taking the original set of 444 trees, the reweighting scheme based on the rescaled consistency index was applied. Four iterations of character reweighting resulted in a stable set of three trees. The consensus of these three trees is shown in Fig. 11. This tree is fully resolved except for the basal polytomy between Syneta carinata, the monophyletic group including chrysomelines + Eumolpus + Orsodacninidae (including Aulacoscelis), and the monophyletic group including the 
Table 2. Taxa included in analysis. Classification based on Reid (1995) except for Alticinae and Galerucinae which is based on Seeno \& Wilcox (1982).

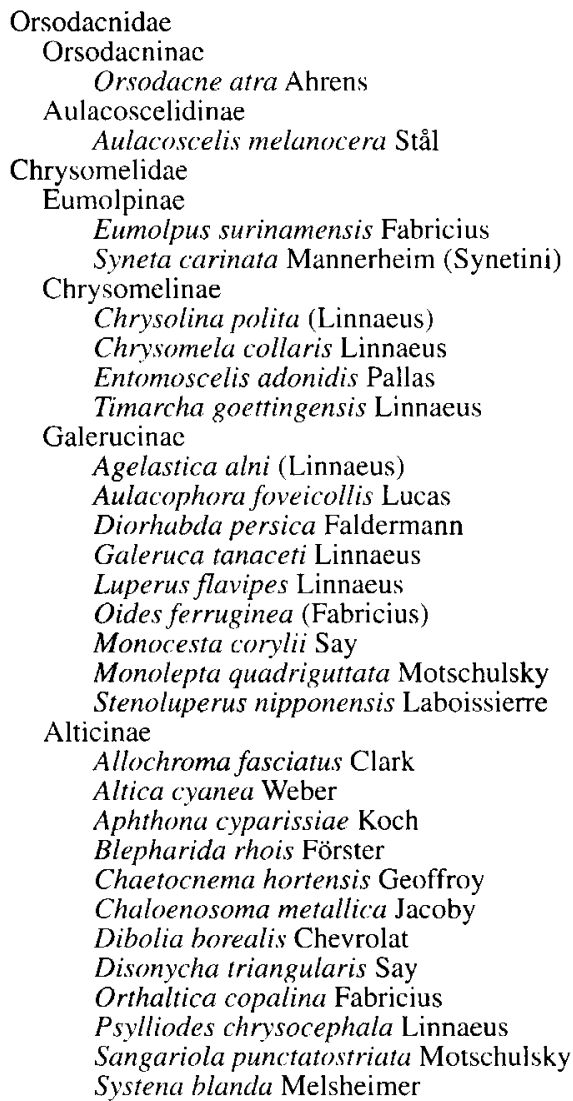

remaining alticines + galerucines. With the exception of the asterisked characters (discussed in next section), characters plotted on this tree are those which show unambiguous support of clades and therefore represent the most conservative optimization. Character support is not indicated on polytomous nodes or discussed since there are multiple, equally parsimonious possibilities.

Lineage support and character distributions. - The successive weighting analysis (Fig. 11) revealed three major lineages as part of a basal trichotomy (Syneta; galerucines with subordinate alticine lineage; chrysomelines + remaining taxa). Their relationships remain obscure because of conflicting basal character support. Because of our conservative character optimization, no characters consis- tently supported the monophyly of alticines + galerucines. However, if we constrain alticines + galerucines to be sister group respectively to Syneta and Chrysomelinae (a widely accepted idea, suggested by: Chapuis 1875, Jacoby 1908, Maulik 1926, Mohr 1966 and Reid 1995), then the same four characters support their monophyly (Fig. 11, Node A): Character $5(0)$, subantennal suture present (reverses at Node B, the alticine lineage); character 10 (1), antennal sockets near each other; 14(2), setose membrane present on inner surface of mandible (reverses in Allochroma Clark); 37(1), vaginal palpi present without membranous attachment (reverses in Blepharida). Forcing a sister group relationship with Syneta does not increase the tree length; however, forcing the sister group relationship to the monophyletic Chrysomelinae increases the length by two steps. The genus Oides Weber was shown to be most primitive among the alticines + galerucines in our sample. The following characters supported the monophyly of the remaining galerucines + alticines at the node above Oides: Character $8(1)$, poorly developed orbital sulcus (becoming well-developed in most of the traditional alticines sampled); character 50(1), transverse metatibial surface dorso-apically (this character reverses in the alticine lineage at node C).

All sampled taxa formerly considered as Alticinae (as listed in Table 2) fell as a strongly supported monophyletic lineage nested within the Galerucinae (Fig. 11, Node B) and sister group to Monolepta. The characters supporting the monophyly of this alticine lineage include: Character 1(2), absence of the midcranial suture (undergoes reversal in Allochroma); character 5(2) absence of the subantennal suture; character $7(1)$, shallow supraorbital sulcus (becoming fully developed in alticine clade immediately above Node $\mathrm{C}$, but highly variable among terminal taxa with alternate equally parsimonious transformations); character 11(1), antennal socket far from eye margin (undergoes a reversal in Blepharida); character 13(1), eye margin distant from mandibular base; character $27(0)$, posterior margin of metapostnotum parallel to posterior margin of metanotum; character $48(1)$, metafemoral spring present (undergoes a reversal in Orthaltica).

Node $\mathrm{C}$ within the alticine lineage (including all sampled alticine genera except Chaelonosoma) is further supported by the following derived states: Character 30(2), metafurcal-mesofurcal tendons of 


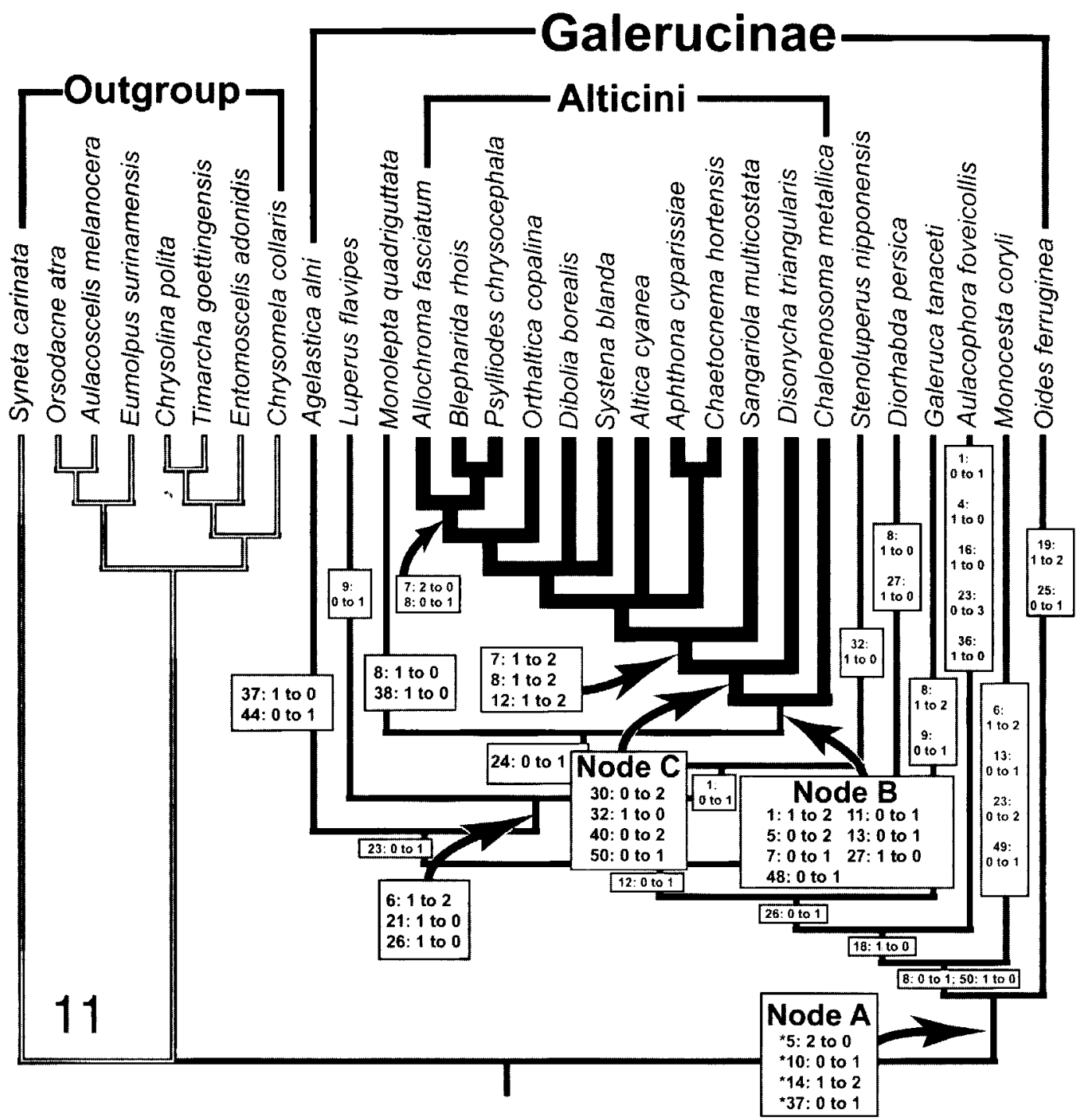

Fig. 11. Strict consensus tree based on the three trees obtained from successive approximations weighting of the original set of 444 most parsimonious trees from the equal weights heuristic analysis.

metendosternite positioned at middle of lateral arms (undergoes independent state changes in $\mathrm{Al}$ lochroma and Orthaltica); character 32(0), apex of lateral arm of metendosternite deflexed with anteapical projection; character $40(2), \mathrm{CuA}_{2}$ of hindwing not intersecting $\mathrm{CuA}$ and short relative to length of $\mathrm{CuA}$ (undergoes independent reversals in Blepharida, Chaetocnema, and Altica; occurring as state 1 in Systena); character 50(1), dorso-apical surface of metatibia with an oblique notch (a re- versal from the state supporting monophyly of altines + galerucines; undergoes yet another reversal in Orthaltica).

For clarity, because of space limitations, unambiguous character states for some nodes (primarily outgroup taxa) were not plotted on Fig. 11, and are therefore listed here. Eumolpus + Aulacoscelis + Orsodacne monophyly is supported by 5 characters: 1 (state 2), 35 (state 1), 36 (state 0), 37 (state 2), and 39 (state 0). Aulacoscelis + Orsodacne 
monophyly is further supported by characters 12 (state 1) and 15 (state 0). Chrysomela, Entomoscelis, Timarcha, and Chrysolina are united by 3 synapomorphies: 25 (state 1), 29 (state 0), and 47 (state 1). Within the alticine clade, Allochroma + Blepharida + Psylliodes is supported by character 8 (state 1). Blepharida and Orthaltica each are shown to be highly derived, with many autapomorphies ( 9 and 10 , respectively).

While evidence supporting the monophyly of alticines + galerucines is not abundant, this is due only to ambiguity with their sister relationships to outgroup taxa. Resolving this ambiguity in favor of synetines does not cost our hypothesis anything in terms of ad hoc assumptions. Resolving the ambiguity in favor of a sister group relationship to chrysomelines requires two additional ad hoc explanations for character convergence. Importantly, if the alticine lineage is constrained to be the sister group to the remaining galerucines, it would require 16 additional explanations of character convergence! Therefore, this study has demonstrated that alticines are a highly derived monophyletic lineage nested deeply within Galerucinae. They represent one of several lineages within Galerucinae and cannot be of equal taxonomic status to Galerucinae either as a subfamily or tribe. Galerucines (whether considered a subfamily or tribe) are paraphyletic unless alticines are included. This change in relative rank of galerucines and alticines with a subordination of alticines is therefore proposed to accurately reflect phylogeny. More work needs to be done to determine the tribal classification within this broadened Galerucinae. Such an endeavor requires much greater taxon sampling than was necessary for this study.

\section{Acknowledgements}

We thank Terry Erwin (Department of Entomology, Smithsonian Institution), Richard Leschen (Landcare, Insect Systematics, Auckland, New Zealand), Allen Norrbom (Systematic Entomology Laboralory, PSI, ARS, USDA), F. Christian Thompson (Systematic Entomology Laboratory, PSI, ARS, USDA), and Catherine Duckett (Universidad de Puerto Rico, San Juan, Puerto Rico) for critical suggestions to improve this manuscript. Elizabeth Roberts (Systematic Entomology Laboratory, PSI, ARS, USDA) prepared Fig. 4.

\section{References}

Allard, E. 1860. Essai monographique sur les Galcrucites Anisopodes (Latr.) ou description des Altises
d'Europe et des bords de la mer Méditerranée. Annales de la Société Entomologique de France (3) 8: 39-144.

- 1866. Monographie des Alticides tribu de la famille des Phytophages. L'Abeille, Journal d'Entomologie 3: $53,169-417$.

Bechyné, J. \& Springlova de Bechyné. B. 1976. Notes sur quelques Aphthonini nouveax ou peu connus. (Chrysomeloidea - Alticinae) Colcoptera, Phytophaga. Pesquisas 28: 1-15.

Böving, A. G. \& Craighead, F. C. 1931. An illustrated synopsis of the principal larval forms of the order Coleoptera. Entomologica americana (N. S.), 11(1), 35 I pp.

Carpenter, J. M. 1988. Choosing among multiple equally parsimonious cladograms. Cladistics 4: 291-296.

- 1994. Successive weighting, reliability and evidence. Ibidem 10: 215-220.

Chapuis, F. 1875. Histoire naturelle des insectes. Genera des Coléoptères. Vol. Il, Famille des Phytophages. 420 pp. Paris.

Chevrolat, L. A. 1836. Pp. 361-443 in Dejean, P. E.: Catalogue des Coléoptères de la collection de M. le comte Dejean, vol. 5 [2nd ed.], Paris.

Crowson, R. A. 1938. The metendosternite in Coleoptera: a comparative study. Transactions of the Royal Entomological Societr of London 87: 397-415.

- 1944. Further studies on the metendosternite in Coleoptera. Ibidem 94: 273-310.

- 1955. The natural classification of the families of Coleoptera. vii $+187 \mathrm{pp}$. London.

Crowson, R. A. \& Crowson, E. A. 1996. The phylogenetic relations of Galerucinae-Alticinae. Pp. 97-118 in Jolivet \& Cox (Eds): Chrysomelidae biology, Vol. 1: The classification, phylogeny and genetics. 444 pp. Amsterdam.

Doguet, S. 1994. Coléoptères Chrysomelidae, Volume 2, Alticinae. Faune de France 80, 697 pp. Paris.

Farrell, B. D. 1998. 'Inordinate Fondness' explained: Why are there so many beetles? Science 281,24 July: 555-559.

Farris, J. S. 1969. A successive approximations approach to character weighting. Systematic Zoology 18: 374385.

Furth, D. G. \& Suzuki, K. 1994. Character correlation studies of problcmatic genera of Alticinae in relation to Galerucinae (Colcoptera: Chrysomelidae). Pp. 116135 in Furth (Ed.): Proccedings of the Third International Symposium on the Chrysomelidae, Beijing, 1992. Leiden.

Gressitt, J. L. \& Kimoto, S. 1963. The Chrysomelidae (Coleoptera) of China and Korea. Part 2. Pacific Insects Monograph Ib: 743-893.

Gruev, B. \& Tomov, V. 1986. Coleoptera, Chrysomelidae. Part II. Chrysomelinae, Galerucinae, Alticinae, Hispinae, Cassidinae. Fauna of Bulgaria 16, 388 pp. Sofia.

Heikertinger, F. 1912. Unterfamilic: Halticinae. Pp. 143212 in Reitter (Ed.): Fauna Germanica. Die Käfer des Deutschen Reiches, vol 4. Stuttgart.

- 1924. Dic Halticinengenera der Palaearktis und Nearktis. Bestimmungstabelle. Koleopterologische Rundschau 9: 25-70.

- 1941. Bestimmungstbellen europäischer Käfer. LXXXII. Fam. Chrysomelidae. 5. Subfam. Haltici- 
nae. Bestimmungstabelle der gattungen der Palaeark tischen Halticinen. Ibidem 26: 67-89.

Heikertinger, F. \& Csiki, E. 1939. Chrysomelidae: Halticinae I. In Junk (Ed.): Coleopterorum catalogus 166: 1-336. s'Gravenhage.

Heikertinger, F. \& Csiki, E. 1940. Chrysomelidae: Halticinae II. Ibidem 169: 337-635. s'Gravenhage.

Horn, G. H. 1889. A synopsis of the Halticini of boreal America. Transactions of the American Entomological Society 16: 163-320.

Jacoby, M. 1908. Coleoptera: Chrysomelidae, vol. 1. In Bingham (Ed.): Fauna of British India including Ceylon and Burma. 534 pp. London.

Jolivet, P. H. A. \& Cox, M. L. (Eds). 1996. Chrysomelidae biology. Vol. 1: The Classification, phylogeny and genetics. 444 pp. Amsterdam.

Konstantinov, A. S. 1998a. On the structure and function of the female genitalia in flea beetles (Coleoptera: Chrysomelidae: Alticinae). Proceedings of the Entomological Society of Washington 100: 353-360.

- 1998b. Revision of the Palearctic species of Aphthona Chevrolat and cladistic classification of the Aphthonini (Coleoptera: Chrysomelidae: Alticinae). Memoirs on Entomology, International no. 11,429 pp.

Konstantinov, A. S. \& Lopatin. I. K. 1987. Comparative morphological study of the metendosternite in the leaf-beetles of the subfamily Alticinae (Coleoptera: Chrysomelidac). Revue d'Entomologie de l'URSS 66: 247-255.

Konstantinov, A. S. \& Vandenberg, N. J. 1996. Handbook of Palearctic flea beetles (Coleoptera: Chrysomelidae: Alticinae). Contributions on Entomology, International 1: 237-439.

Latreille, P. A. 1802. Histoire naturelle, générale et particulière, des crustacés et des insectes. Tome troisième. Familles naturelles des genres. xii +468 pp. 'An X', Paris.

Lawrence, J. F. \& Britton, E. B. 1994. Australian beetles. 192 pp. Carlton.

Lee, J. E. 1993 Phylogenetic studies on the larvae of the Chrysomelidae (Coleoptera) from Japan. Japanese Journal of Entomology 61: 409-424.

Lingafelter, S. W., Konstantinov, A. S. \& Lee, J. E. 1998. Systena Chevrolat (Coleoptera: Chrysomelidae: Alticinae): notes on nomenclature, redescription of the genus, and a preliminary discussion of characters and phylogenetic relationships. Proceedings of the Entomological Society of Washington 100: 467-483.

Lopatin, I. K. 1984. Leaf beetles (Chrysomelidae) of Central Asia and Kazakhstan. 416 pp. New Delhi.

Maddison, W. P. \& Maddison. D. R. 1992. MacClade: Analysis of phylogeny and character evolution, Version 3.0.5. Sunderland, Massachusetts.

Mann, J. S. \& Crowson, R. A. 1981. The systematic position of Orsodacne Latr. and Syneta Lac. (Coleoptera Chrysomelidae), in relation to characters of larvae, internal anatomy and tarsal vestiture. Journal of $\mathrm{Nat}$ ural History 15: 727-749.

- 1984. On the digitiform sensilla of adult leaf beetles (Coleoptera: Chrysomelidae). Entomologia generalis 9: 121-133.

Maulik, S. 1926. Coleoptera, Chrysomelidae (Chrysomelinae and Halticinae). In Shipley (Ed.): Fauna of British India, including Ceylon and Burma. 442 pp. London.
Medvedev, L. N. 1982. Leaf beetles of MPR. Identification guide. 302 pp. Moscow.

Mohr, K.-H. 1966. 88. Familie: Chrysomelidae. Pp. $95-$ 280 in Freude, Harde \& Lohse (Eds): Käfer Mitteleuropas, vol. 9. Krefeld.

Newman, E. 1835. Attempted division of British insects into natural orders. Entomological Magazine 2: 379431.

Ogloblin, D. A. 1936. Leaf beetles, Galerucinae. Fauna of USSR 26(1): 455 pp. Moskva \& Leningrad [in Russian].

Redtenbacher, L. 1874. Fauna Austriaca. Die Käfer, nach der analytischen Methode bearbeitet. 3rd ed. 571 pp. Wien.

Reid, C. A. 1995. A cladistic analysis of subfamilial relationships in the Chrysomelidae sensu lato (Chrysomeloidea). Pp. 559-631 in Pakaluk \& Slipinski (Eds): Biology, phylogeny, and classifications of Coleoptera: Papers celebrating the 80th birthday of Roy A. Crowson. 1092 pp. Warszawa.

Samuelson, G. A. 1996. Binding sites: Elytron-to-body meshing structures of possible significance in the higher classification of Chrysomeloidea. Pp. 267-290 in Jolivet \& Cox (Eds): Chrysomelidae biology, vol. 1: The classification, phylogeny and genetics. Amsterdam.

Scherer, G. 1969. Die Alticinae des indischen Subkontinentes (Coleoptera - Chrysomelidae). Pacific Insects Monograph no. 22, $251 \mathrm{pp}$

Seeno, T. N. \& Wilcox, J. A. 1982. Leaf beetle genera (Coleoptera: Chrysomelidae). Entomography no. 1, $221 \mathrm{pp}$.

Snodgrass, R. E. 1935. Principles of insect morphology. 667 pp. New York.

Stephens, J. F. 1839. A manual of British Coleoptera, or beetles; containing a brief description of all the species of beetles hitherto ascertained to inhabit Great Britain and Ireland; together with a notice of their cheif localities, times and places of appearances, etc. 443 pp. London.

Suzuki, K. 1992. The systematic position of the subfamily Aulacoscelinae (Coleoptera: Chrysomelidae). Pp. 45-59 in Furth (Ed.): Proceedings of the Third International Symposium on the Chrysomelidac, Beijing. Leiden.

- 1994. Comparative morphology of the hindwing venation of the Chrysomelidae (Coleoptera). Pp. 337-354 in Jolivet, Cox \& Petitpierre (Eds): Novel aspects of the biology of Chrysomelidae. The Netherlands.

- 1996. Higher classification of the family Chrysomelidae (Coleoptera). Pp. 3-54 in Jolivet \& Cox (Eds): Chrysomelidae biology, vol. 1: The classification, phylogeny and genetics. Amsterdam.

Suzuki, K. \& Furth, D. F. 1992. What is classification? A case of study in insects systematics: potential confusion before order. Zoological Science 9: 1113-1126.

Swofford, D. L. 1991. Phylogenetic Analysis Using Parsimony (PAUP), version 3.1.1. Smithsonian Institution, Washington, D. C.

Winkler, A. 1929. Catalogus coleopterorum regionis palaearcticae. Vol. 10,1360 pp. Wien.

Revised manuscript accepted October 1999. 